\title{
KEEPING CONCEPTUALIZATIONS SIMPLE: EXAMPLES WITH FAMILY CARERS OF PEOPLE WITH DEMENTIA
}

\author{
Georgina M. Charlesworth \\ University College London, UK \\ F. Katharina Reichelt
}

Bolton, Salford \& Trafford Mental Health Trust, UK

\begin{abstract}
This paper forms the second in a series of three articles on conceptualizations of older people's distress. The focus is on simple and concrete "mini-formulations" that keep the amount of information in them to a minimum, yet retain explanatory and predictive power. Such formulations can be used as the basis for action plans for intervention, while avoiding overburdening the cognitive capacity of the client or therapist. Simple linear and cyclical models are described, as are cognitive triad and dyad models. The uses of "mini-formulations" for group and individual settings are illustrated in a case example of a lady caring for her husband who has dementia.
\end{abstract}

Keywords: Conceptualization, formulation, complexity, older adults, caregiving, dementia.

\section{Introduction}

The characteristics, purpose and methods of case conceptualization for cognitive therapy have been described by various authors (e.g. Bruch \& Bond, 1998; Persons \& Tompkins, 1997). The case for formulation in cognitive therapy for older adults has been made by Laidlaw and colleagues (2004), who expand the cognitive model of emotional disorders to encompass cohort beliefs, role investments, intergenerational linkages, sociocultural context and health beliefs. The Laidlaw et al. model highlights key contextual factors that will assist therapists' understanding of older clients' life experiences, and the impact that these have on the client's perspective in the "here and now". However, the comprehensive nature of the model may make it somewhat unwieldy and potentially overwhelming for some clients.

Comprehensive formulations may outstretch the cognitive capacity of the client and/or therapist in cases where clients have multiple difficulties in the context of adverse life circumstances, or where clients have limited cognitive capacity due to overwhelming distress or cognitive impairments. The greater the cognitive impairments of a client, the more concrete

Reprint requests to Georgina Charlesworth, Lecturer in Clinical \& Health Psychology of Old Age, Centre for Behavioural and Social Sciences in Medicine, University College London, Wolfson Building, 48 Riding House Street, London W1W 7EY, UK. E-mail: g.charlesworth@ucl.ac.uk 
the focus of therapy. This limits options for formulation, and the therapist must be flexible in his/her approach in order to maximize the client's strengths and compensate for his/her disabilities. For example, demands on memory may need to be reduced and "pre-therapy" skills, such as identifying and labelling emotions and thoughts, may need to be learned.

A comprehensible formulation is more likely to be accepted than one that is comprehensive but perceived by the client as incomprehensible. In the spirit of Beck's exhortation that we "simplify, simplify, simplify" (Beck, Emery, \& Greenberg, 1985), and Butler's call for parsimony (Butler, 1998, p. 5), methods of formulating are required that use the minimum necessary information to summarize a problem and provide the rationale for an action plan. Examples of simple, comprehensible "mini-formulations" form the focus of this paper, and are explored below. The mini-formulations used include short linear chains of appraisal and emotional response, two or three element vicious cycles and cognitive triads and dyads.

\section{Mini-formulations}

\section{Linear chains}

The basic cognitive appraisal model of "event $\rightarrow$ appraisal $\rightarrow$ emotional response" has been superseded in recent cognitive therapy literature by more elaborate cognitive models for specific disorders. However, a return to the basic linear chain can be useful in educating a therapy-naive client to the phenomenon of appraisal. The model can be used in most circumstances as long as the term "event" is defined broadly to encompass both external and internal experiences including life events, actions of others, and the client's own thoughts, emotions and body sensations.

\section{Mini-cycles}

Padesky and Mooney's (1990) 5-element generic cognitive model, colloquially known as the "hot cross bun", highlights the inter-relationships between cognition, affect, behaviour and physiology in the individual's environmental context. However, for some clients, the number of elements, and the use of bi-directional arrows, represents too much information. Charlesworth (1999) suggested that shared formulation with older adults can be facilitated through the use of 2- and 3-element "mini-cycles" derived from the Padesky and Mooney model. The classic example of this is the "feel low $\rightarrow$ negative thoughts and sad memories $\rightarrow$ feel worse" mood-thought cycle. Other common examples would be the "pain $\rightarrow$ depression $\rightarrow$ pain exacerbation" cycle that can be used in conjunction with educational material such as the gate control theory of pain (Melzack \& Wall, 1996). Once a client feels comfortable with the most simple diagrammatic and narrative formulation, it can be elaborated as necessary to encompass other salient aspects of functioning.

\section{Cognitive triads}

Whereas mini-cycles may not initially include a cognitive element, cognitive triads and dyadic models are exclusively cognitive descriptions of an emotional state. Cognitive triads are derived from Beck's models of content specificity (Beck, 1976) and concern the perception of the self, the world and the future. For example, a typical triad for depression may be "I'm worthless", 
Table 1. Cognitive themes associated with emotional distress

\begin{tabular}{lll}
\hline Relationship & Emotion & \multicolumn{1}{c}{ Themes } \\
\hline Triads & Depression & $\begin{array}{l}\text { Sense of self as worthless or inadequate, with negative view of } \\
\text { world \& future } \\
\text { Sense of vulnerability, perception of the environment as chaotic, } \\
\text { and the future as unpredictable. }\end{array}$ \\
& Anxiety & $\begin{array}{l}\text { Sense of personal injustice, perception of the environment as hostile, } \\
\text { a need to act to protect self from future harm } \\
\text { Sense of self as an object of ridicule or humiliation as judged by } \\
\text { someone in the environment. Shame is interpersonally driven } \\
\text { (Gilbert, 1994) }\end{array}$ \\
& Shame & Sense of the self as being the source of harm or injury, with someone \\
& in the environment suffering as a result of one's actions.
\end{tabular}

\footnotetext{
${ }^{1}$ Depression, anxiety and anger are represented by triadic relationships. However, other emotions such as shame and guilt are better described by dyadic relationships.
}

"The world is punishing", "The future is bleak", whereas the corresponding triad for anxiety would be "I'm vulnerable", "The world is threatening/chaotic", "The future is unpredictable". James $(1999,2001,2002)$ has used the cognitive triad format to elucidate the typical thoughts associated with the emotion of anger, for example "I'm being used/abused", "The world is hostile", "The future is dangerous". The characteristic themes are summarized in Table 1, along with the themes of cognitive dyads.

\section{Cognitive dyads}

Dyadic rather than triadic themes have been proposed to explain emotions such as guilt and shame (Gilbert, 1994). As for triadic themes, such frameworks have proven useful in conceptualizing people's experiences of distress and, in practice, encourage therapists to pay careful attention to clients' emotional states.

\section{Mini-formulations for complex cases}

Treatment for complex cases has often been based on complex and comprehensive conceptualization models (e.g. see Tarrier, Wells, \& Haddock, 1998). However, clients with difficulties in multiple domains are often those least able to engage with such formulations. One common example of complexity within the older adults specialty is formulation for family caregivers, as it involves the "here and now" and historical experiences of two people, as well as the interactions between them. Where the care-recipient is a person with dementia, an added level of complexity arises due to their cognitive limitations and the implications this has for a cognitively demanding talking therapy.

Caregivers are often looking for ways to make sense of both their own and the carerecipient's emotional and behavioural reactions. In the absence of verbal information from a care-recipient, carers are likely to use their own emotional state as the source material on which to base assumptions of the others' behaviour and motivations. They are at risk of making the cognitive errors of "personalization" and "mind-reading" often seen in couples (Beck, 1988). In addition, caregivers commonly appraise their own performance (Noon, 1999). Unsupported 
caregivers who are responsible for care-recipients exhibiting challenging behaviours may appraise their caregiving as inadequate and be at risk of self-blame and depression. Caregivers who appraise their coping strategies as inadequate may respond to the care-recipient with high Expressed Emotion (hostility, critical comments) that may act to exacerbate challenging behaviours in the client and serve to reinforce the sense of poor coping self-efficacy in the carer (Barrowclough \& Parle, 1997).

Cognitive therapy has been shown to be an effective intervention for carers of people with dementia for addressing distressing emotions such as depression and anger (Coon, Thompson, Steffen, Sorocca, \& Gallagher-Thompson, 2003). A number of manuals are now available, outlining useful cognitive and behavioural skills such as thought challenge, assertiveness, stress management, pleasurable activity scheduling and relaxation (e.g. Gendron, Poitras, Dastoor, \& Perodeau, 1996; Olshevski, Katz, \& Knight, 1999; manuals listed in Laidlaw, Thompson, DickSiskin, \& Gallagher-Thompson, 2003, Appendix 2). However, case formulation has generally been notable by its absence from the caregiving literature.

We suggest that use of selected mini-formulations can be of benefit in work with family caregivers, and provide an opportunity for caregivers to explore both intra- and interpersonal issues raised by caregiving. A typical caregiving example is given below, derived from experiences from numerous family carers of people with dementia. The example highlights the use of linear and cyclical models, in addition to illustrating the way in which triadic and dyadic models can be used to support carers to learn to empathize with the experience of their impaired relative through monitoring the care-recipient's mood and behaviour.

\section{Case example}

Mrs C was a 72-year-old lady attending a group for family carers of people with dementia. Her husband of 47 years had been diagnosed with Alzheimer's Disease two years previously, and had recently started to urinate in the bedroom sink during the night. Mrs C felt helpless and unable to control any aspect of the situation. She was upset that $\mathrm{Mr} \mathrm{C}$ ignored her repeated pleas for him to stop, was angry that he was making a mess on the carpet and walls, and felt embarrassed on his behalf that he should be doing such a thing when he had always been a fastidiously clean person. She also described grieving for the loss of the man whom she had known for so many years, and feeling guilty for shouting at him.

Following a visit by Mrs $\mathrm{C}$ to her general practitioner, $\mathrm{Mr} \mathrm{C}$ (who was registered at the same practice) was referred to an older person's community mental health team for assessment of his challenging behaviour. Once the couple were in contact with health services, Mrs C was invited to join a CBT group for carers of people with dementia. In common with other group members, Mrs $\mathrm{C}$ was experiencing a number of powerful, interrelated emotions in the context of an unwanted life circumstance. She was determined to do the best that she could for her husband, but her physical exhaustion (through lack of sleep) and emotional exhaustion in the face of a chronic deteriorating illness were now getting in the way of her ability to problem-solve day-to-day hassles, thereby increasing her sense of feeling overwhelmed.

In discussing carers' experiences in the group, "mini-formulations" were generated to summarize the thoughts and emotions experienced. In a session on "looking after ourselves" a simple 2-element vicious cycle (Figure 1a) highlighted the relationship between a sense of low coping self-efficacy and low mood, giving the group leader the opportunity to empathize with the difficulty of the caring situation, while simultaneously educating the group on 
(i)

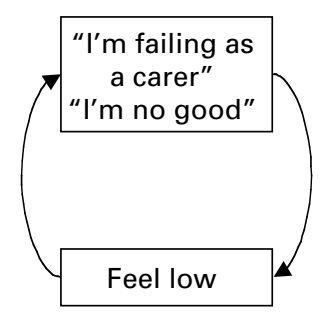

(ii)

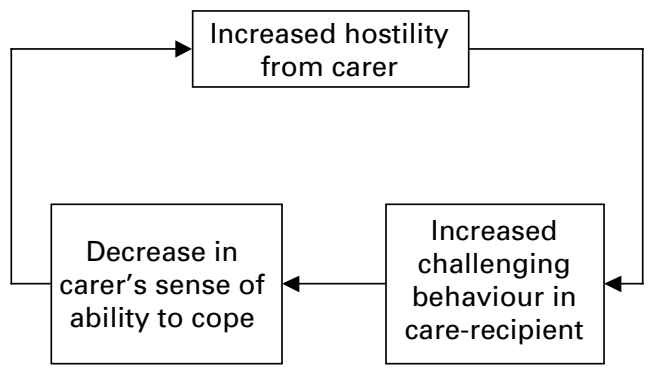

(iii)

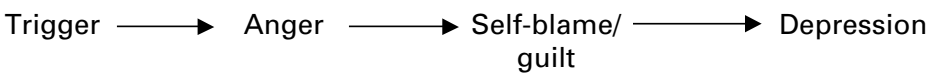

Figure 1. Mini-formulations for Mrs C

both the dynamic interconnection between thoughts and emotions, and the attentional and mnemonic processes that match mood and reinforce beliefs. Participants were also encouraged to notice and value the times when they had been successful in caregiving tasks. A "chain" of emotions and appraisals was drawn up for the shared experience of anger and subsequent guilt (Figure 1c). Carers were encouraged to be compassionate with themselves over their angry feelings, and alternatives for angry responses were discussed. In a session on "understanding challenging behaviour" the basic 2-element cycle was expanded to include the impact on the care-recipient (Figure 1b), based on Barrowclough and Parle's (1997) cycle of relapse and Expressed Emotion.

Mrs C felt comforted knowing that she was "not the only one" to experience feelings of frustration and guilt. However, her increased understanding of her own internal state did not provide any additional insight into her husband's situation. Negative automatic thoughts such as "He knows what he's doing" and "He's only doing it to wind me up" would still trigger anger, especially when she had woken in the night to see her husband again urinating in the sink. Yet she could see his discomfort and distress, and became confused over his level of awareness.

Use of triadic formulations helped Mrs C to consider her husband's mental state and helped her gain insight into the moment-to-moment dynamics of the emotional shifts during the nighttime episodes. Figure 2 outlines typical interactions between $\mathrm{Mr}$ and $\mathrm{Mrs} \mathrm{C}$, which start at the point when Mrs $\mathrm{C}$ found her husband urinating in the sink. Some of the statements attributed to $\mathrm{Mr} \mathrm{C}$ in the triads were generated by Mrs C and the therapist, and were seen as "best guesses". However, the "guesses" are based on observable information about Mr C's behaviour, body language and expressed mood rather than "mind-reading" assumptions arising from Mrs C's mood state.

When Mrs C saw her husband's "inappropriate" urination, her anger was triggered and she would shout at him. He would be startled and become abusive towards her (no-one had 
Mrs C's Triads

\section{Triggering behaviour}

Mr C caught urinating in the sink in the downstairs bathroom by his wife.

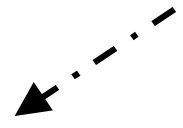

Mr C's Triads *

\section{Anger triad}

There's no regard for my efforts to keep things clean; He's lazy and doing this on purpose; I can't let this go!

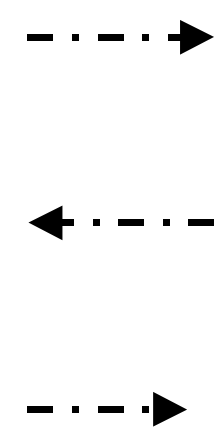

shouldn't get shouted at! He's an ungrateful $* * *$;

I'll teach him not do this again.

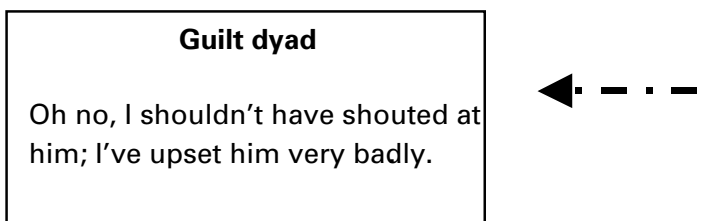

\section{Anxiety triad}

Oh no, I'm doing "something" wrong; Things are confusing; I feel lost; I used to be so sure of myself and the things I did.

\section{Depression triad}

I'm an awful carer and wife; No one can help; Things are only going to get worse.

\footnotetext{
* Owing to Mr C's cognitive difficulties, he was unable to reflect on the incidents. Hence, his triads were derived collaboratively between the therapist and Mrs $\mathrm{C}$. The therapist used circular questions, frequently used in systemic therapy (eg. if you were in your husband's position, how might you respond to that anger?), to help her both gain better insight and to generate her husband's triad.
}

Figure 2. Mapping the triads for Mr and Mrs C 
shouted at him like this since he was a child!). She responded to his abuse by becoming more aggressive; she was determined that she would not back down because "... standards must be maintained". Frequently Mr C became more aware that he had done something inappropriate and became quiet and withdrawn, looking confused and frightened. This response triggered the feelings of guilt and depression that were now recognized by Mrs C from her work in the group.

The process of generating the triadic conceptualizations with the therapist helped Mrs $\mathrm{C}$ to gain a better insight into her husband's perspective, and gave her the opportunity to reappraise the situation. She was able to appreciate that Mr C's confused and anxious appearance was inconsistent with her negative automatic thought that he was being intentionally uncouth and ill-mannered. Thus, Mrs C was able to challenge her automatic thoughts that he was purposefully "winding her up", and instead she was able to explore alternative hypotheses for her husband's behaviour. For example, his inappropriate urinating may have been due to visual problems (Was he mis-identifying the porcelain sink for the toilet?) or some other physical or cognitive difficulties (urinary urgency, prostate problems, disorientation). Exploration resulted in some practical solutions to reduce the likelihood of the distressing behaviour (e.g. putting more clues around the sink to highlight its true function, putting a light over the sink to aid visual identification, starting a regular 2-hourly toileting programme, and putting a commode in the room), and reduce the impact of the consequences of the behaviour (e.g. tiling the wall, and putting absorbent matting down near the sink). Through taking action and seeing changes in Mr C's behaviour, Mrs C's sense of coping efficacy increased.

The dyadic and triadic formulations used in the group and individual work helped Mrs $\mathrm{C}$ to normalize her responses to different situations, understand intra- and inter-personal dynamics, challenge unhelpful appraisals and generate new interventions. Mrs C was able to re-evaluate some of her unrealistic cognitions about being a carer, and she moved away from negative, global statements about herself, the world or the future. She was able to accept that she was likely to experience the occasional extreme negative emotional response (anger, frustration, transient hate) as a natural part of the caring process. Such acknowledgements served to prevent the exacerbation of guilt and depression, and perhaps the build-up of emotions that may lead on to abuse.

\section{Conclusions}

This brief paper has outlined some simple CBT conceptualizations that can be used with clients naïve to a psychological approach and/or those who think in a concrete way, irrespective of age. The mini-formulations described contrast markedly with Laidlaw et al.'s more comprehensive framework, which, while much richer in content, may be more difficult to employ directly with clients in sessions owing to its relative complexity.

The case example focused on a family carer, but the "mini-formulation" frameworks can be used also with paid carers on wards and in residential and nursing settings. Staff in such settings have been shown to commonly attribute such behaviours as being purposeful acts arising from unchangeable characteristics of the people in their care (Bromley \& Emerson, 1995; Cottle, Kuipers, Murphy, \& Oakes, 1995).

It could be argued that mini-formulations are easier for clients to engage with, and therefore likely to facilitate greater collaboration and teamwork between client and therapist. Once a client has engaged with a basic formulation, they may be interested to elaborate their shared 
understanding with the therapist, as described by Kinderman and Lobban (2000). The issue of collaboration in conceptualizations is discussed more fully in the third and final paper in this series on formulations (Charlesworth \& Greenfield, 2004).

\section{References}

Barrowclough, C., \& PARle, M. (1997). Appraisal, psychological adjustment and expressed emotion in relatives of patients suffering from schizophrenia. British Journal of Psychiatry, 171, 26-30.

BECK, A. T. (1988). Love is never enough: How couples can overcome misunderstandings, resolve conflicts and solve relationship problems through cognitive therapy. New York: Harper \& Rowe.

BECK, A. T. (1976). Cognitive therapy and the emotional disorders. New York: International Universities Press.

Beck, A. T., EMERY, G., \& GReEnBerg, R. L. (1985). Anxiety disorders and phobias: A cognitive perspective. New York: Basic Books.

Bromley, J., \& EMERSON, E. (1995). Beliefs and emotional reactions of care-staff working with people with challenging behaviour. Journal of Intellectual Disability Research, 40, 166-175.

BRUCH, M., \& BOND, F. W. (1998). Beyond diagnosis: Case formulation approaches in CBT. Chichester: Wiley.

BUtLer, G. (1998). Clinical formulation. In A. S. Bellack \& M. Hersen (Eds.), Comprehensive clinical psychology (Vol. 6), pp. 1-24. Oxford: Pergamon.

CHARLESWORTH, G. (1999). Cognitive therapy case formulation with older adults. PSIGE Newsletter, $69,27-30$.

Charlesworth, G., \& Greenfield, S. (2004). Overcoming barriers to collaborative conceptualization in cognitive therapy with older adults. Behavioural and Cognitive Psychotherapy, 32, $411-422$.

Coon, D. W., Thompson, L., Steffen, A., Sorocca, K., \& Gallagher-Thompson, D. (2003). Anger and depression management: Psychoeducational skill training interventions for women caregivers of a relative with dementia. The Gerontologist, 43, 678-689.

Cottle, M., Kuipers, L., Murphy, G., \& OAKes, P. (1995). Expressed emotion, attributions and coping in staff who have been victims of violent incidents. Mental Handicap Research, 8, 168-183.

Gendron, C., Poitras, L., DAstoor, D. P., \& Perodeau, G. (1996). Cognitive-behavioural group intervention for spousal caregivers: Findings and clinical considerations. Clinical Gerontologist, 17, 3-19.

GILBERT, P. (1994). Counselling for depression. London: Sage.

JAMES, I. A. (1999). Using a cognitive rationale to conceptualize anxiety in people with dementia. Behavioural and Cognitive Psychotherapy, 27, 345-351.

JAMES, I. A. (2001). Cognitive therapy formulations and interventions for treating distress in dementia. In C. Ballard, J. O'Brien, I. James \& A. Swann (Eds.), Management of behavioural and psychological symptoms in dementia. Oxford: Open University Press.

JAMES, I. (2002). Treatment of distress in people with severe dementia using cognitive behavioural concepts. In S. Benson (Ed.), Dementia topics for the millennium and beyond. London: Hawker Publications.

Kinderman, P., \& LOBBAn, F. (2000). Evolving formulations: Sharing complex information with clients. Behavioural and Cognitive Psychotherapy, 28, 307-310.

Laidlaw, K., Thompson, L. W., Dick-Siskin, L., \& Gallagher-Thompson, D. (2003). Cognitive behaviour therapy with older people. Chichester: Wiley.

Laidlaw, K., Thompson, L. W., \& Gallagher-Thompson, D. (2004). A comprehensive conceptualization of cognitive behaviour therapy for late life depression. Behavioural and Cognitive Psychotherapy, 32, 389-399. 
Melzack, R., \& Wall, P. D. (1996). The challenge of pain. London: Penguin Science.

Noon, J. M. (1999). Counselling and helping carers. Leicester: BPS Books.

Olshevski, J. L., Katz, A. D., \& KNIGHT, B. G. (1999). Stress reduction for caregivers. London: Brunner/Mazel.

PAdesky, C. A., \& Mooney, K. A. (1990). Presenting the cognitive model to clients. International Cognitive Therapy Newsletter, 6, 13-14.

Persons, J. B., \& TompKins, M. A. (1997). Cognitive-behavioural case formulation. In T. D. Eells (Ed.), Handbook of psychotherapy case formulation. London: Guilford Press.

TARRIER, N., Wells, A., \& HADDOCK, G. (1998). Cognitive therapy for complex cases. Chichester: Wiley. 